\title{
THE USE OF FILM-BASED MATERIAL FOR AN ADULT ENGLISH LANGUAGE COURSE IN BRAZIL*
}

\section{O USO DE MATERIAIS BASEADOS EM FILMES PARA UM CURSO DE INGLÊS NO BRASIL}

\section{Leonardo Lucena Parisi Nick Andon}

\begin{abstract}
Advances in technology and accessibility to films motivated the research and writing of this paper. Its main goal was to design a set of criteria to develop film-based materials that can be used to improve the experience of learning English on an adult conversation course in Brazil. Given that the purpose of this adult course is to enhance participants' speaking skills, an investigation was conducted into the theories related to the teaching of speaking. A literature review suggests why films should be used through an investigation into the advantages they offer. Principles related to language learning, material development, and current studies on the use of film provide insights on how films might be used. Drawing on these principles, a set of criteria was created as a resourceful guide for material development. Finally, I suggest there should be further study on how films are being used in class and a possible research study on the effectiveness of film-based materials.
\end{abstract}

Keywords: films; language learning; material development.

\section{RESUMO}

Avanços em tecnologia e acessibilidade à filmes motivaram a pesquisa e a composição desse artigo. O objetivo principal foi desenvolver um conjunto de critérios para criação de materiais baseados em filmes com o fim de aperfeiçoar a aprendizagem de inglês em um curso de conversação no Brasil. Dado que o propósito deste curso para adultos é aprimorar as habilidades de fala dos alunos, uma investigação foi conduzida sobre o ensino da fala. A discussão da literatura sugere porque filmes devem ser usados através de uma investigação sobre as vantagens que eles oferecem. Princípios relacionados à aprendizagem de línguas, desenvolvimento de material didático, e estudos atuais sobre o uso de filmes proporcionaram maior conhecimento sobre como filmes podem ser usados. A partir desses princípios, critérios foram criados para guiar o desenvolvimento de materiais didáticos. Finalmente, eu sugiro futuros estudos sobre como filmes estão sendo usados em sala de aula e uma possível pesquisa sobre a eficácia de materiais didáticos baseados em filmes.

Palavras-chave: filmes; aprendizagem de idiomas; desenvolvimento de material.

\footnotetext{
*King’s College London, London, England. leonardolparisi@gmail.com; King’s College London, London, England. nick.andon@kcl.ac.uk
} 


\section{INTRODUCTION}

Advances in technology, such as the development of digital video and the popularization of video-streaming websites, have made films more easily accessible for purposes of language learning. Along with availability, films might benefit the learning experience by providing authentic input, raising cultural awareness, motivating students, and creating opportunities for language production.

In spite of these advantages, many teachers still feel hesitant about working with films in class, and often rely on them solely for entertainment purposes. This may be the result of a lack of training on how to make effective use of films in a classroom setting. For this reason, I decided to develop this study, which aims to (a) advocate for the use of films in teaching, and (b) present a set of guidelines for choosing and using films.

A discussion of empirical and theoretical literature will be presented to answer the questions of why films should be used and how they could be used. The literature review will also provide relevant background knowledge for designing materials. The set of criteria I designed is intended to fulfill the objectives of a specific course, and the emphasis is therefore on oral production. Nonetheless, they could still be adopted as helpful guides for other teachers in similar contexts.

The material was developed in accordance with the objectives of a Conversation Course I taught for two years at the Federal University of Paraiba in Brazil. The Department of Modern Foreign Languages offers this six-month course for university-level students who wish to continue their learning of the English language. The classes take place twice a week, with each class lasting for two hours. Students can gain entry to the Conversation Course either by completing a three-year course (also offered by the Department) or by passing a proficiency test in case the maximum number of twenty students is not reached.

The three-year English course from which most students come integrates all four skills (reading, writing, listening, and speaking). There is a strong focus on grammar throughout its three course books (one for each year). Therefore, when learners arrive for the Conversation Course, they have an average level of upperintermediate proficiency in English, but are in need of extra speaking practice over and above the other skills.

Although some of the students' goals may vary, most of them have one want in common when they join the course: to practice their speaking skills. This has been precisely the goal of the Conversation Course since it was created. Students need to be provided with enough speaking opportunities to improve their communicative 
competence. Focus on form is no longer stressed in most classes. The classes should have greater emphasis on practicing speaking through interaction and increased student talking time by exposing them to different topics. Since no single course book is adopted, the teacher has the freedom to use his/her creativity and experience however they see fit in order to develop materials to accomplish the goal of the course.

During my two years spent teaching these classes, I learned that most students regularly watch American and/or British films and TV series, both as a tool for learning and also for pleasure. Thus, it seemed appropriate to develop materials that make use of videos in order to motivate learners in class. Exposure to videos would also provide a break from students' previous limited experience of working mostly with written texts. Many of the other benefits of using films and TV series in language learning will be discussed later. In short, by taking into consideration (a) the overall goal of the Conversation Course, (b) the students' needs and wants, and (c) their enjoyment of films and TV series, the use of videos for learning purposes would be appropriate.

This article has been divided into five chapters. Chapter 2 presents an overview of theories related to the teaching of speaking. The main advantages of using films in language teaching will be investigated in Chapter 3, as well as some principles with regard to language acquisition, materials development, and the text-driven approach. Techniques for using films are discussed in Chapter 4. Finally, Chapter 5 provides a conclusion with a brief summary of the study and some final considerations.

\section{TEACHING SPEAKING}

Even though the primary objective of this article is to advocate for the use of films for language learning, the main goal of the Conversation Course is to provide students with opportunities to practice their speaking skills. Thus, this section will present a discussion of learning theories related to speaking, including (a) dichotomies such as knowledge and skill, motor-perceptive and interaction skills, and cognitive and affective processes, (b) the importance of interaction and output, (c) the role of speech acts, and, finally, (d) some practical implications related to the design of activities that focus on speech production.

First, a distinction can be made between speaking divided into knowledge and skill (BYGATE, 1987). The latter is defined by Bygate as the ability to produce and adapt utterances according to the circumstances, whereas the former is the abstract notion of how to compose perfect sentences, i.e., what the student knows 
about the structure of a language, including, for example, grammar, vocabulary, and pronunciation. However, spoken discourse, as argued by Hughes (2010), is not a neat combination of grammatically accurate sentences, as is usually the case in formal writing. Therefore, speaking as a skill should have greater focus on the teaching material, in order to give students the necessary practice to learn how to use the target language.

Bygate (1987) divides speaking into two skills: motor-perceptive skills and interaction skills. Motor-perceptive skills involve identifying and producing the sounds and structures of the language in the correct order. This skill is commonly practiced in the audiolingual approach, which is influenced by a behaviorist notion and emphasizes the use of repetition (BURNS and HILL, 2013). When practicing this skill, learners produce language determined by the teacher, often in a contextfree environment. Even though motor-perceptive skills are important for language learning, their excessive practice without integration of interaction skills has been criticized as depriving learners of control of their own language (WILKINS, 1974). Consequently, it is more appropriate when teaching speaking to allow students to make their own decisions about what to say and how to say it. This ability to use language according to specific demands is defined by Bygate (1987) as interaction skill, and is more relevant than motor-perceptive skills to the context for which I designed the material.

Hughes (2010) points out that collaboration between speakers should be one of the aims of materials aimed at developing speaking. During collaborative dialogues, students are provided with comprehensible input and opportunities for output. It is through input that learners are given positive evidence of what is possible in the target language (GASS and MACKEY, 2015). Output, on the other hand, provides negative evidence, in other words, information about the incorrectness of what was said. Gass and Mackey (2015) also point out - based on Swain's (2000) observations - at least two other advantages of output: hypothesis testing and automaticity. The former refers to the learner's opportunity to try out words or sentences where there is uncertainty as to their correct usage, whereas the latter involves the routinization of language, i.e., reducing the effort of producing some utterances by making it a more automatic process.

In order to become an effective speaker, one also needs to be familiar with different types of speech acts. Nunan (1999, p. 131) briefly defines them as "simply things people do through language," i.e., utterances that perform some kind of function, such as complaining, apologizing, agreeing, requesting, and so on. Speech acts represent an important aspect of language that cannot be disregarded when 
teaching a foreign language, especially since despite being seemingly universal in their typology, speech acts can be expressed differently across different cultures (VAEZI et al., 2014).

When designing materials, other aspects of the speaking process should also be considered. Similarly to Bygate's aforementioned work, Burns and Hill (2013) also divide speaking into two parts: cognitive process and affective process. From a cognitive perspective, materials should ensure that learners have (a) enough linguistic knowledge, (b) background knowledge, and (c) articulation, in order to be able to express meaning. These issues should be taken into account when selecting films and designing activities. The pressure of having to speak in class might create nervousness among students; therefore, from an affective perspective, reducing anxiety should be another goal. Different interaction patterns can be used in order to make students feel more comfortable, and personal questions might be more suitable for pair work.

Drawing on the work of Ur (1996), the following set of implications for teaching spoken English is suggested when designing materials:

a. Learners should have most of the talking time during the class. Use of group work is encouraged to increase their participation;

b. Classroom discussions should have students participating as equally as possible. A minority of students should not dominate the discussion;

c. The material should be motivating. Topics and tasks should be chosen carefully. Clear purpose and interesting topics are more likely to engage students and increase their participation.

This section has provided a clearer understanding of the theories related to the teaching of speaking, as well as considerations that might benefit the designing of materials. Some of the theories discussed here provided greater influence than others for the development of a set of guidelines for using film-based material, such as the importance of (a) plenty of opportunities for output and interaction, and (b) exposure to and practice of speech acts and idiomatic expressions.

\section{WHY USE FILMS IN LANGUAGE TEACHING?}

The first part of this section will discuss the principles concerning language acquisition and materials development that provided guidance for the design of 
the set of criteria. In addition, the text-driven approach (TOMLINSON, 2003) will be briefly explored as it has also played an important role in my context. The second part of the section will focus on the advantages of using films and their role in language teaching.

\subsection{Principles and material development}

When designing materials, teachers need to have some principles to guide them with regard to language learning. Ellis (2005) provides a set of ten principles. He points out that these are not intended to be used prescriptively, but rather as suggestions and a basis for reflection. Therefore, not all of his principles were relevant for my context. For example, focus on form is an important principle, and students should practice language features such as grammar and pronunciation; however, given the goals of the course, other principles were emphasized. The following is a list of the principles that had a greater influence on the design of this material:
i. Provide a rich repertoire of formulaic expressions;
ii. Focus on meaning;
iii. Provide extensive L2 input;
iv. Provide opportunities for output;
v. Provide opportunities for interaction;
vi. Take into account individual differences.

According to the first principle, students need to be exposed to different formulaic expressions. Idioms, collocations, and set phrases play an important part in communication, and are often used by native speakers (GILMORE, 2007). Therefore, students should practice with formulaic expressions in order to develop fluency, and films are a rich source of exposure to these natural language features. "Focus on meaning" refers to the need for students to be provided with tasks in which they can perform pragmatic meaning, which can be described as the highly contextualized meanings that arise out of the use of language as a means of communication. This is important because only through focusing on pragmatic meaning will language acquisition take place, as well as it developing fluency and being intrinsically motivating (ELLIS, 2005). Providing extensive L2 input (principle 'iii') refers to the need to maximize exposure to the target language in class, and opportunities must also be created for students to receive L2 input outside the classroom. Principle 'iv' is the same as the main goal of the Conversation Course, 
which acknowledges the importance of language production. Principle ' $v$ ' refers to interaction, in which students are given the opportunity to negotiate meaning while benefiting from input and output simultaneously. The individual differences mentioned in principle 'vi' include aptitude and motivation. Ellis suggests that teachers can cater to aptitude by applying flexibility and variety to the activities. On the other hand, motivation, as argued by Dörnyei and Ushioda (2001), may be fostered in many different ways, including the presentation of interesting and relevant material.

Besides knowledge of how languages are acquired, teachers should also be aware of what the literature has to offer with regard to the design of materials. Tomlinson (2010) proposes a set of principles for materials development that draws on most of the aforementioned principles of language acquisition. In brief, materials should provide:

i. Plenty of authentic spoken and written texts, presented in a contextualized way;

ii. Potential for engagement, both affective and cognitive;

iii. Interesting, relevant, enjoyable, yet challenging texts and tasks;

iv. Opportunities to produce the language through meaningful and authentic tasks.

Similar to the principles for language acquisition, this set of principles is also intended to provide guidance and should not be seen as a concrete set of rules.

Once a set of principles for both language acquisition and materials development has been adopted by the teacher, s/he should decide what kind of approach is more fitting for the specific students, context, and goals. The TextDriven Approach (TOMLINSON, 2003) features elements that seem effective for my context and for the use of films. In short, this approach uses a text - which can be written or spoken - as the main support for the whole lesson. First, the text must be carefully chosen, as all of the subsequent material is going to be derived from it. Tomlinson provides criteria for text selection that are very similar to the set of principles for material development previously mentioned in this section. After the text has been selected and tested by the teacher, $\mathrm{s} /$ he must devise readiness activities (TOMLINSON, 2003, p. 113). In other words, the teacher will mentally prepare students for their forthcoming experience with the text. Examples of readiness activities include asking students to visualize, articulate opinions, make predictions, and many other different techniques intended to engage their thinking. The next 
step is designing experiential activities to be performed while the students are exposed to the text, so that they can experience the text instead of merely observing it as an object of study. Then, learners are invited to reflect on what the text meant to them and articulate their opinions and feelings as part of intake response activities. Tomlinson also suggests development activities, in which learners should be encouraged to go back to the text in order to produce meaningful language. Finally, the framework of the text-driven approach uses input response activities, which are divided into interpretation tasks and awareness tasks. The former refer to activities designed to develop critical thinking, such as debating the issues in the text, analyzing reviews, asking deep questions, and so on. The latter examples refer to activities that raise students' awareness of language features, including language use, communicative strategies, and discourse. Tomlinson (2003, p. 116) emphasizes that this "framework is best used flexibly" and that "there is no need to follow all the stages," therefore, some adaptations were taken in order to provide a better fit to the students' needs and pedagogical goals of my context.

When designing materials that use films, some researchers have studied their benefits and suggested a wide variety of applications (STEMPLESKI and ARCARIO, 1990; BADDOCK, 1991; SHERMAN, 2003; MISHAN, 2005; DONAGHY and WHITCHER, 2015), which will be further discussed in Section 4. MacDonald and MacDonald (1991) summarize in three steps what is necessary for a successful film course: (a) selecting a film according to the purposes of the class, (b) developing support material, and (c) designing tasks that motivate students.

With the support of principles and approaches to developing a framework to work with films, as well as having a clear understanding of films' benefits and of which techniques might be more suitable, the teacher can finally start developing the material by selecting the films to be used. For the film selection process, McGrath's (2013) criteria for choosing authentic texts provide a helpful guide:

- Relevance

- Interest of topic

- Cultural appropriateness

- Linguistic demands

- Length

- Exploitability

Learners will have more to gain if the material is relevant and interesting. They will be more likely to feel motivated if they can enjoy and relate to the topic 
chosen (MCGRATH, 2013). Teachers should also be careful with regard to a film's cultural appropriateness, as some topics might be considered inappropriate for discussion in class within the context of certain cultures. The language used in the film should not be too complex for the level of the students, or it may have the effect of demotivating them. The length should be appropriate for the goals the teacher sets out to accomplish, as well as the time available. Finally, the film's exploitability will provide the necessary means for the teacher to develop tasks.

These criteria are very similar to those developed specifically for films and suggested by authors such as Donaghy and Whitcher (2015) and Goldstein and Driver (2015). Drawing on Arcario (1990), two more criteria can be added: independence of sequence and visual support. The film needs to provide sufficient visual elements to aid in students' listening comprehension. Moreover, if scenes are to be used independently from the rest of the film, care should be taken to ensure that the sequences chosen can - at least to some extent - stand on their own and do not require too much in the way of background exposition.

\subsection{Advantages of using films}

The use of films in class can offer many benefits for learners. This section will cover some of the main advantages provided by films and their role in language teaching/learning; more specifically, the role of authenticity, motivation, cultural awareness, and the development of language skills (both receptive and productive).

\subsubsection{Authenticity}

The benefits to a learner of moving to an English-speaking country are undeniable. The process of immersing oneself in a context in which the target language is spoken provides the learner with extensive input and exposure to the foreign culture. However, not everyone can afford to or is able to travel abroad to study. Thus, it becomes essential to create materials that expose the linguistic and cultural features of English. One way of achieving this is to use authentic materials in class.

There is a wide variety of definitions relating to the term "authentic." In his seminal article, Gilmore (2007) quotes eight possible meanings from various authors, but he eventually agrees with Morrow (1977, in GILMORE, 2007, p. 98), who defines "authentic" as "a stretch of real language, produced by a real speaker or writer for a real audience and designed to convey a real message of some 
sort." Compared to other authors who, for example, claim "authentic" is language produced by native speakers (PORTER and ROBERTS, 1981), or Widdowson (1978), who claims such a quality can only be bestowed in relation to the reader/ listener, in my opinion, Morrow seems to provide a more suitable definition for the term in relation to films. A film is authentic if it was not produced with the sole purpose of teaching language, but rather to convey a real message or feelings to the audience. Therefore, in contradiction to Porter and Roberts, even if the characters portrayed are not native speakers, a film can still be considered authentic. With regards to Widdowson's point of view, I believe the relationship between material and learner will affect the film's effectiveness, not its authenticity; after all, learners with different levels of proficiency might be able to cope with authentic material if it has been carefully selected by the teacher. Nevertheless, it is still advisable for students to watch movies with authentic purposes in order to make better use of the authentic material (GILMORE, 2007).

Regardless of the continuing debate over the definition of "authenticity," the potential of authentic materials to benefit language learning is almost unquestionable. While course books have at times been criticized for their misrepresentation of language and culture (GILMORE, 2007; MCGRATH, 2013), the use of authentic materials such as films has been encouraged (SHERMAN, 2003; MISHAN, 2005; DONAGHY and WHITCHER, 2015). However, as Gilmore (2007) points out, contrived materials do not necessarily mean "bad," just as authentic materials do not necessarily mean "good." For example, a Shakespearean sonnet, even though it is an authentic text, might not be linguistically appropriate for lower-level students; on the other hand, literature students with a high level of proficiency may derive great benefit from it. The effectiveness of whichever material the teacher chooses to use is also going to depend on other aspects, such as (a) the context, (b) who his/ her students are, and (c) what goals need to be achieved. Thus, a set of guidelines related to the selection of authentic material ought to be helpful.

After having properly selected the authentic material to be used, some of the advantages that it might provide include its potential to effect improvements in the leaners' linguistic, pragmalinguistic, and discourse competence (GILMORE, 2007). From a linguistic perspective, students are exposed to more natural use of the language, including formulaic sentences, such as idioms and collocations. Course books' depiction of certain speech acts are often misrepresented; for example, direct complaints are frequently dealt with, while in reality indirect complaints are more common in real interaction (BOXER and PICKERING, 1995). Authentic materials, on the other hand, would be more likely to raise pragmatic awareness, 
as Boxer and Pickering (1995, p. 56) suggest that "only through material that reflects how we really speak, rather than how we think we speak, will language learners receive an accurate account of the rules of speaking in a second or foreign language." Discourse competence would also be developed by exposing students to realistic samples of conversations to illustrate how people manage conversations, and how discourse strategies such as turn-taking would be used.

Besides exposing students to a rich variety of real language use, other advantages of using authentic material in class include raising cultural awareness and motivating learners. These benefits of authenticity will be further investigated discretely in the following sections as they also provide some of the reasons for integrating films in materials development and language learning.

\subsubsection{Motivation}

As a key advantage of using videos in class, motivation is considered by many authors and teachers to be one of the most significant variables that influence language learning (DÖRNYEI and USHIODA, 2001; DE BOT et al., 2005; BROWN, 2007). I will investigate some of the theories related to motivation that can help teachers understand the role of this fundamental factor affecting learning, and which can provide helpful insights during the development of teaching materials.

According to Brown (2007), some historical schools of thought have influenced the way motivation is perceived, notably the behavioral, cognitive, and constructivist perspectives. The behaviorist approach focuses on the anticipation of reward as the main driving force to accomplish a goal. From a cognitive point of view, individuals' needs are emphasized. Some of these needs include the need for exploration, stimulation, knowledge, and ego enhancement (2007, p. 169). Finally, a constructivist view also takes into account the needs of the individual, but combines them with a stronger emphasis on social context. Films can work better at motivating students from both a cognitive and constructivist point of view.

Motivation can also be divided into three hierarchical levels: global, situational, or task-oriented (BROWN, 2007) (similarly represented by Dörnyei and Ushioda (2001) as global, contextual, and situational). The global level refers to the general orientation of learners toward learning a foreign language. The situational level represents the students' engagement in a particular learning context, such as the classroom. The task-oriented level refers to the students' approach to a given task and/or their willingness to perform well in specific aspects of the language, such as learning grammar or pronunciation. It seems that the task-oriented type of 
motivation is more easily influenced by the teacher's actions and the activities s/ he develops. Therefore, it would make sense to focus one's effort on the design of engaging materials in order to encourage learner motivation.

A third distinction related to motivation concerns the notion of intrinsic and extrinsic motivation. Brown (2007, p. 170) distinguishes between the two by claiming that "those who learn for their own self-perceived needs and goals are intrinsically motivated, and those who pursue a goal only to receive an external reward from someone else are extrinsically motivated." It is also worth mentioning that learners are not necessarily only intrinsically or extrinsically motivated, as the two types frequently overlap. A student could be motivated to fulfill his or her personal desire to learn a foreign language and, at the same time, be engaged in a task to receive a good grade or avoid some kind of punishment.

Both intrinsic and extrinsic motivation can be influenced by the teacher. Although it may seem difficult for a teacher to influence a learner's extrinsic motivation (e.g., motivation resulting from parental expectations), there are still ways in which this can be achieved. Since learners who have previously succeeded in a task are more likely to engage in future activities (UR, 1996), it would be crucial for teachers to make students aware (even through a simple gesture such as nodding) that they have been successful. The satisfaction gained as a result of receiving praise from the teacher would most likely increase the student's extrinsic motivation (UR, 1996). Intrinsic motivation, on the other hand, can be more easily developed by teachers. At a global level, for example, teachers could show interesting and relevant information about the language. Fostering intrinsic motivation at a taskoriented level, on the other hand, is more closely related to the design of materials and activities. Drawing on Ur (1996) and Brown (2007), some of the suggestions to increase such motivation (which could also be supported - at least to some extent - by the use of videos) would include: showing relevant material that appeals to the interests of the learners; making students aware of the purpose of the tasks they are engaged in; using visual aids; providing reasonable challenges; and presenting a variety of topics.

Another important aspect of motivation is that it changes over time (DÖRNYEI and USHIODA, 2001). This is especially significant my context, where most students have already been studying English for a period of approximately three years. Williams and Burden (1997) argue that it is essential not only to stimulate students' motivation, but to also sustain their interest over time. Moreover, Gass and Selinker (2001, p. 354) claim that motivation to succeed in long-term projects, such as learning a foreign language, depends on fostering 
motivation through a series of short activities, as "willpower must be summoned frequently at various points in time to overcome different resistances." Therefore, one's overall motivation to learn English might not be sufficient, and teachers therefore have to develop meaningful and engaging tasks in addition to interesting materials. Videos can be a rich source of meaningful tasks that could help maintain students' motivation.

Since films are already perceived as a medium of entertainment, it seems reasonable that, if properly selected, they would also serve to encourage students' motivation in a class setting. Furthermore, films motivate students by providing visual clues that facilitate comprehension. According to research by Cross (1984, in GILMORE, 2007), demonstrating to learners their ability to cope with authentic material will motivate them. A similar argument is made by King (2002), who points out that understanding a film will enhance the students' confidence and, consequently, have a positive impact on their motivation.

Other ways of motivating students are included in the "10 commandments" suggested by Dörnyei and Csizér's (1998, p. 215) empirical research, some being more easily fostered through the use of films than others. For example, films can promote the commandment "Make the language classes more interesting," as well as providing flexibility to satisfy the commandment "Personalize the learning process." Dörnyei and Csizér also claim that teachers should "familiarize learners with the target language culture" (1998, p. 215). Gaining exposure to the cultural aspects of a foreign language through the watching of films has additional advantages besides motivating students, as will be outlined in the next section.

\subsubsection{Cultural Awareness}

Raising cultural awareness is a crucial part of the learning process, as Atkinson (1999, p. 625) claims that "except for language, learning, and teaching, there is perhaps no more important concept in the field of TESOL than culture" (emphasis from original). Before discussing the benefits of raising cultural awareness, and how films can help to realize this objective, it is essential to understand some of the issues relating to the term culture.

Hua (2014, p. 01) briefly defines culture as "a system of values and practices of a group or community of people." However, the definition of culture has been constantly debated, and a distinction between "Culture" (with a capital " $\mathrm{C}$ ") and "culture" (with a small " $\mathrm{c}^{\text {") }}$ ) is often made (2014, p. 01). Art, literature, and food are all part of "Culture with a capital ' $\mathrm{C}$ '," and provide a simplistic view of the culture 
of the target language (HINKEL, 1999). On the other hand, "culture with a small "c'" encompasses broader characteristics of a society, including its values, beliefs, and behaviors.

Although many definitions for culture can be found within the literature, at least one aspect upon which most authors seem to agree is that culture and language are inseparable (KRAMSCH, 1993). According to Atkinson (1999, p. 647) "knowledge of language - including, centrally, how to use it - cannot be developed without at the same time developing knowledge of the sociocultural contexts in which that language occurs." Hua (2014, p. 176) also adds that "language influences thought and worldviews, and therefore differences among languages cause differences in the thought of their speakers." Kay and Kempton's (1984, in HUA, 2014) research on speakers of English and Tarahumara (language spoken by Native American people of northwestern Mexico) supported these claims when it showed the different ways color terms were perceived.

In addition to working as a motivating force for students, as mentioned in the previous section, and being inseparable from language itself, the raising of cultural awareness brings even more benefits to the learning process. Exposing students to other cultures allows them to reflect and understand even more their own culture (GILMORE, 2007). Otherwise, they may assume that the foreign culture functions in the same way as their own. This exposure might also help students understand the moral values of the target community and, consequently, stimulate empathy toward it (ISTANTO, 2009). Moreover, other specific fields of the target culture might be further explored, such as architecture, history, geography, and so on, depending on the students' interests.

It is crucial to point out that raising cultural awareness is not realized simply through showing students films or other authentic materials in isolation; it is also necessary to develop learners' cultural sensitivity so as to enable them to fully grasp the cultural message. One way of doing this is by drawing comparisons between the target and local cultures, which might lead to deeper explorations that can improve students' intercultural communicative competence (MISHAN, 2005).

The use of movies can be a rich source of foreign culture exposure for students as, Sherman (2003, p. 2-3) argues, film is a "window on English-language culture," and she later adds that "a small amount of showing is worth hours of telling from a teacher or course book." In comparison to other teaching aids, Herron et al. (1995) claim that films illustrate the target culture more effectively. For example, popular films can be used to depict cultural movements, such as Selma (2014) and the struggle against segregation in the USA; sectors of society can also be portrayed, 
as in, for example, Secrets and Lies (1996) focusing on the British working class; potentially controversial issues, such as abortion, can be found in films like Juno (2007). Furthermore, a wide variety of communicative situations (e.g., apologizing, thanking, complaining, and many others) can be portrayed in films and given more emphasis during class activities.

Another advantage of showing films as a way to raise cultural awareness is the use of visual cues that allow learners to observe the non-verbal aspects of communication (e.g., body language, facial expression, proxemics, etc.) that are often culture-specific and cannot be found in written or audio-only materials. Films might be used to promote close observation followed by a class discussion on the ways in which people interact, as students point out what can be inferred about the target culture from body language and other elements of paralanguage.

In this section, I have illustrated that raising cultural awareness to improve intercultural communicative competence in students is essential in the languagelearning process and that films can work as an effective tool to provide such awareness. After discussing advantages of films that involve the role of authenticity, motivation, and culture in language teaching, I will focus in the next section on the goal of most English courses and investigate how films can facilitate the development of language skills.

\subsubsection{Language Skills}

The sole act of watching a film can work as an interesting input for students to practice their listening skills. However, the benefits of using films are not limited to listening skills. Enough research evidence (EKEN, 2003; ISTANTO, 2009) has concluded that, among other advantages of using films, the motivating context created by them helps the practice and enhancement of all four language skills. Therefore, in addition to listening, films can provide a favorable context in which to develop reading, writing, and speaking.

With regard to the receptive skills (listening and reading), films allow students to use bottom-up and/or top-down processes (HEDGE, 2000). The former has learners constructing meaning starting from words or sounds, whereas the latter involves the use of contextual clues and prior knowledge to reach a meaningful interpretation. When showing a film, teachers can use the bottom-up strategy to have students focus on the use of specific language to understand the message. In contrast to this, teachers may adopt a top-down strategy and activate the students' schematic knowledge, defined by Hedge (2000, p. 232) as "the mental 
frameworks we hold in our memories for various topics, " by introducing the topic before showing the video. Then, students can focus primarily on the gist of the film, and only later move on to the linguistic aspects of the message. However, it is worth mentioning that even though activities can focus more on one strategy than the other, both processes usually take place simultaneously, as comprehension (either from listening or reading texts) is enabled by a combination of linguistic information, contextual clues, and prior knowledge.

Another advantage of using films to develop listening skills is their portrait of authentic informal talk. Even though films are scripted, their language can be considered authentic in the sense that it is not graded or simplified for non-native speakers, and is considered more realistic than the language found in textbooks. Sherman (2003, p. 13) argues that films are "the nearest thing most foreignlanguage students have to real-life experience of spoken meaning." Different from many recordings made for teaching purposes, which usually have features such as repeated structures, slow pace, grammatically correct sentences, and lack of ellipses, films can expose students to a variety of grammatical structures, variations in the speed of delivery, colloquial language, and other features of natural spoken language, such as ellipsis and elision (HEDGE, 2000). Moreover, films provide visual clues that facilitate comprehension, and the visual presence of the speaker gives a more realistic exposure to how most listening situations occur outside the classroom (UR, 1996). Research also shows that overall listening comprehension can be enhanced by using subtitles in English when showing videos (KING, 2002). English-language subtitles may also benefit the students' reading skills as they practice rapid reading.

One of the goals of reading is to "build schematic knowledge in order to interpret texts meaningfully" (HEDGE, 2000, p. 205). Therefore, the reading of texts can be used in pre-viewing activities to engage students with the topic. Reviews and synopses are some examples of texts that could be used prior to watching a film. Some texts could also be used to create comparisons with the film, such as short stories or novels adapted to film, biographies of characters based on real life, and/or news article about the main topic. Using authentic texts and creating meaningful purposes for reading will motivate students (UR, 1996).

Films can also work as springboards to develop productive skills (speaking and writing). One example of how they can improve speaking skills is by having students role-play scenes from the film, which helps to contextualize the task, thus making even accuracy-based activities more meaningful. Furthermore, the topics of a film, especially controversial ones, can spark lively debates that help improve 
fluency (ALTMAN, 1989). Films can also work as stimuli or input for activities that involve discussion in pairs or small groups and other opinion-gap tasks, which are useful ways of developing speaking skills (HEDGE, 2000). As for writing skills, teachers can assign written projects and provide opportunities for students to gather ideas and plan what they are going to write, and the final draft could be done as homework in order to save classroom time. Some examples of writing activities might include: writing a review of the film, in which students could express their personal opinions; writing a synopsis, which could test their comprehension of the film; and writing a different ending to the story, allowing students to be creative.

In conclusion, it seems undeniable that films can be a beneficial resource in the enhancement of language learning. Their advantages, as discussed here, range from providing exposure to authentic language use, motivating students and raising cultural awareness, to practicing language skills. Other benefits of using films could be added, such as the addition of flexibility and variety to the syllabus, as a form of entertainment, a means of lowering anxiety, and the fact that they are easily accessible, and so on.

\section{HOW TO USE FILMS}

In the interests of making the most of showing films to students, teachers should also familiarize themselves with the different techniques of working with them. This section will explore the wide variety of applications that the use of film places at the teacher's disposal. The advantages and disadvantages of different approaches to film will be discussed, such as the use of whole movies or short sequences, captioned and non-captioned, and pre-viewing, while-viewing, and post-viewing activities. However, possible challenges that may arise when using films will be addressed first, as well as some suggestions as to how to overcome them.

\subsection{Overcoming difficulties}

What may have been intended for use as a motivating material can in actual fact turn into a frustrating experience for students. The list of advantages of using films may be long, but there are still some issues teachers need to keep in mind in order to overcome possible difficulties. Problems may arise from technical difficulties, choosing the wrong film, or from using it in an ineffective way. 
With regard to the film itself, Sherman (2003) points out some aspects of the language portrayed that may hinder comprehension, for instance: strong regional accents and dialects, such as Brad Pitt's character in the film Snatch (2000), who is barely understood by the other characters in the film; period language, found in adaptations of period novels or historical films; and high verbal density, i.e., too much speech and too little action (e.g., most Woody Allen films). Teachers can avoid these obstacles by carefully evaluating the film prior to selecting it. Another problem teachers might encounter when showing films in class is what Harmer (2001, p. 283) calls "the 'nothing new' syndrome," which refers to the act of watching films just for the sake of it, offering nothing different from watching them at home. Therefore, in order to avoid learner passivity, interesting and meaningful while-viewing tasks should be designed (STEMPLESKI, 1990). Once these potential obstacles have been overcome, students will be more likely to reap the benefits that films have to offer.

Technical difficulties may also hinder the viewing experience. For example, the equipment might not work. Teachers should try everything out in advance to make sure they know how to handle all of the devices being used, and that they are all in correct working order. Another potential obstacle is a classroom with poor viewing conditions. The TV or projector must be big enough and high enough so that all students are able to clearly see the film. Speakers also need to be sufficiently loud that students will not have trouble listening to the film. Finally, as most teachers would suggest, it is always good to have a back-up lesson.

\subsection{Whole-film approach}

In the whole-film approach, feature films are presented to students in their entirety. One advantage of this approach is that since the entire film is being watched - just as it was meant to be seen - students will be exposed to the complete communicative process of the film, making this a more authentic type of viewing experience (KING, 2002). King also claims that by being able to comprehend the complete movie, students will feel more confident and motivated.

On the other hand, one of the downsides of showing the entire film to students concerns its running time. Firstly, the length of a feature film might take up almost all of the available classroom time, making it more challenging to then provide students with other activities. Secondly, as Donaghy and Whitcher (2015) and Canning-Wilson (2000) point out, there is enough empirical evidence that suggests students' attention span lasts only a few minutes; consequently, students would become passive viewers of almost the entire duration of the film. However, one way to regain students' 
attention and keep them active whilst viewing the whole feature film is by pausing the video, as if copying the system of commercial breaks, and still keeping some level of authenticity (MISHAN, 2005). Teachers can stop the film to ask questions about what the students have already seen and/or speculate what is yet to come. However, teachers should be careful with this technique, as the constant stopping and resuming of the film might irritate students (HARMER, 2001).

\subsection{Short-sequence approach}

Most authors agree that a better way to present movies is by showing short sequences instead of overloading students with the whole film (STEMPLESKI, 1990; HARMER, 2001; DONAGHY and WHITCHER, 2015). In this approach, the teacher selects one scene, or maybe several scenes, from a feature film to show to students. Besides the obvious advantage of saving time in comparison with the whole-film approach, short sequences can also be a rich source of different activities in class. Stempleski (1990, p. 11) argues that a "2-to 3 -minute sequence can provide enough material for a 1-hour lesson." The choice of scene(s) will depend on the objective for the class, whether it is to generate a topic for discussion, listening practice, exposure to linguistic features, or to raise cultural awareness, for instance. Another advantage of short sequences is the opportunity provided for repeated viewings. Watching the same scene more than once allows the teacher to focus on different aspects of the film with each viewing, such as the language, visual elements, sounds, characters, setting, and so on.

One potential disadvantage of using scenes extracted from a film is that they are, by nature, decontextualized (SHERMAN, 2003). Therefore, it is important for teachers to design pre-viewing activities that provide some kind of introduction and contextualization. Another way of overcoming this issue is by showing students short films. All of the aforementioned advantages of showing scenes also apply to the showing of short films and, in addition, students would benefit from being provided with a complete narrative, with a beginning, a middle, and an end. Thus, the use of short films would maintain the authentic purpose of the film, as the whole-film approach suggests, but without demanding a long attention span from students.

\subsection{The use of captions}

Regardless of the approach being used, whole film or short sequence, teachers still have to ask themselves whether or not they should include captions 
in the film. The word caption is being used here to refer to subtitles in English, and not a translation to the learners' first language, as Sherman (2003, p. 17) argues that in the case of the latter, "there is very little learning of English in this kind of viewing." When deciding whether or not to use captions, teachers need to take into consideration students' proficiency, and the objectives of the viewing activity.

Many authors have argued that showing films with captions in the target language might improve learners' overall comprehension (KING, 2002; SHERMAN, 2003). Research conducted by Garza (1991) on the use of captions with advanced students concluded that besides enhancing language learning, learners also used their reading skills to improve aural comprehension, which helped to bridge the gap between the two skills. His findings also suggested that advanced students can cope with the addition of the textual modality without feeling overloaded with information.

Even though captions provide many benefits, teachers should exercise caution in relation to their use. According to King (2002), subtitles hinder the development of inferring and guessing meaning from context and visual clues. Moreover, reading the captions might become a habit that is hard for learners to break, making them more hesitant to take the next step and remove them in order to have a more authentic experience with viewing a film. King adds that by not using captions students will (a) be encouraged to increase their tolerance for ambiguities, (b) make use of inference skills, and (c) feel a greater sense of accomplishment.

\subsection{Viewing techniques}

Drawing on Williams's (1984) model that suggests three stages for reading comprehension, films can be exploited in the same way. Divided into pre-viewing, while-viewing, and post-viewing stages, each stage will have its own purposes and a wide variety of activities that can be developed alongside it. The application of these techniques will vary according to the pedagogical goals the teacher has designed for the use of films.

\section{Pre-viewing}

According to Stoller (1990), the main purpose of pre-viewing activities is to activate the students' schemata. This means tapping into their prior knowledge of the theme present in the film, which will help learners to better understand the narrative. Besides introducing the topic, Kusumarasdyati (2004) adds that 
pre-viewing activities often include pre-teaching of key vocabulary. They can also be divided, as suggested by Donaghy and Whitcher (2015), into language- and communication-based activities. The goals of these activities are not mutually exclusive, and they usually overlap.

If the focus of the pre-viewing stage is on language, an activity that could be developed is handing out lists for students to match the key vocabulary from the film with their definitions (the same could be done with collocations). From a communication-based perspective, on the other hand, making predictions might be an interesting way of engaging learners. Students might be asked to guess the plot of the film based on its title or on a still image from the film. Another activity to engage students with the topic is making a semantic map (STOLLER, 1990), by having them brainstorm words related to the theme of the movie. Some activities might provide practice for both language- and communication-based goals, for example, integrating reading input (e.g., the synopsis of the film), which exposes students to words that might come up in the video, in addition to introducing the topic.

\section{While-viewing}

The activities in this stage are aimed at helping students maintain focus on the film (MISHAN, 2005). However, teachers should be careful not to overload students with too many tasks to perform while viewing, otherwise the activity might become frustrating and the entertainment value of the film lost (DONAGHY and WHITCHER, 2015). For example, students can be given a set of comprehension questions to be answered only after they have watched the film. By doing this, students will remain focused on the film and not have to listen and write at the same time.

Besides focusing on their general comprehension of the film, students can also be instructed to focus on different aspects, such as plot development, the characters, or other more specific information (STOLLER, 1990). Similarly to one of the pre-viewing activities, teachers may also raise students' curiosity while they watch the movie. One way this can be done is by stopping the film in the middle of a scene and asking students to predict what will happen next; or perhaps showing the end of a scene and asking students to speculate what might have happened before (STEMPLESKI, 1990). Another technique that plays with learners' curiosity is playing the film without the sound, so students have to guess what the characters are saying. This technique, referred to as "silent viewing" by Harmer (2001, p. 
286), could also have students focus on the role of body language, and perhaps look for nuances within gestures or facial expressions that differ from those of the local culture.

\section{Post-viewing}

Once students have finished watching the film, the teacher can use its input as a springboard to develop a variety of activities. Mishan (2005) argues that the most authentic post-viewing activity is talking about the film. Students could express their thoughts about the film, whether they liked it or not, their favorite moments or characters, and so on. According to Mishan, this activity could be followed by discussions that focus on more specific aspects, such as linguistic and/ or cultural features. Donaghy and Whitcher (2015) also point out that it is highly effective for language learning to have students reflect on what they have watched and relate that to their personal experiences. For example, students could compare their prior knowledge of the topic with what they have learned from the movie. In another example, as argued by Pegrum et al. (2005), learners could benefit from comparing the differences between their own culture and the culture of the target language.

Other follow-up activities could include: debates over controversial topics; comparisons between film and book $k_{i}$ expressing agreement or disagreement with reviews; role-playing scenes; and many others. Harmer (2001) suggests that this stage could also be used to spark learners' creativity. The teacher could ask students to imagine how the scenes would play out in different circumstances, such as changing the gender of the characters, time period, or setting. As discussed in Section 3.2.4, post-viewing activities stimulate not only oral but also written production. For instance, students could be asked to write their own reviews, alternative endings, and suggestions for sequels or prequels.

Based on the literature review presented thus far, which has included input from principles of language acquisition, teaching speaking, materials development, and the text-driven approach, I designed a set of general guidelines for using films with the purpose of teaching language. These guidelines are meant to be seen as suggestions that could be adapted depending on the context and its pedagogical purposes. They include:

i. Cater to all language skills (speaking, listening, reading, and writing)

ii. Use authentic material and authentic tasks 
iii. Provide plenty of interaction

iv. Engage the students affectively

v. Practice formulaic expressions

In summary, I have discussed why and how films can be used to promote language learning. The advantages of using films described in Section 3.2 will be more or less emphasized according to the techniques the teacher chooses to use. Eventually, the decision of how to show the movie and which activities are going to be assigned will depend on the pedagogical goals the teacher is trying to achieve

\section{CONCLUSION}

Based on the discussion of the literature review, it was possible to achieve the first aim of the paper and answered the question of why films should be used by focusing on (a) the advantages of their application in class, and (b) how their use can match different principles with regard to language learning. The second aim was also discussed in the literature review, as techniques and approaches to the use of films suggested how teachers could make the most of their use. Finally, it was possible to create a set of criteria that would help on the development of film-based materials.

The criteria was designed to match the goals of a Conversation Course from the Federal University of Paraiba in Brazil. The main goal of the course is to provide students with plenty of opportunities to practice speaking. The students are mostly young adults with an upper-intermediate level of proficiency, who decide to join the class to improve their speaking skills. During the two years I taught this course, the majority of learners shared that they enjoyed watching English-language films and TV series. Therefore, the choice of using films seemed suitable to motivate the students and improve their learning experience by emphasizing the development of their speaking skills. Even though the criteria was created to fulfill the objectives of a specific course, theoretical and empirical research have suggested that the use of film offers a wide variety of applications that could be suitable for different contexts.

Given the goal of the Conversation Course, principles with regard to teaching speaking were taken into consideration during this study. As Hughes (2010) suggests, interaction plays a major role in the development of speaking skills. When engaging in collaborative dialogue, students are given the opportunity to benefit from receiving input and providing output simultaneously. Another important point 
when teaching speaking, as argued by Nunan (1999), is to provide enough exposure and practice with speech acts, so learners will be able use language to accomplish specific goals.

Principles related to language acquisition and materials development also influenced this paper. The final framework designed to meet the goals of the specific context included the following principles:
i. Cater to all language skills (speaking, listening, reading, and writing)
ii. Use authentic material and authentic tasks
iii. Provide plenty of interaction
iv. Engage the students affectively
v. Practice formulaic expressions

The text-driven approach developed by Tomlinson (2003) should help organize the structure and design of activities in order to meet each criterion from this framework.

The advantages discussed in Section 3.2 answer why films can be considered a rich source of material for language teaching. The benefits of using films include:

- Authenticity: being an authentic material, films are more likely to do a better job at portraying how language is used in real life than course books;

- Motivation: since the first objective of films is to provide entertainment, they can also be considered a great source of motivation;

- Cultural awareness: films allow students to reflect on their own culture and, consequently, become more affectively engaged in the learning process;

- Language skills: films offer opportunities to practice all of the main language skills. Films can provide input to improve receptive skills, and can work as a springboard to develop activities that benefit productive skills.

These were some of the benefits investigated in this paper that support the claim that films can provide fruitful material to enhance language learning. Through investigation of these advantages, it has been possible to develop a better understanding of the role each plays in the process of language learning.

Another goal was to show bow films could be used. Based on the literature review, Section 4 offers suggestions of how films could be used in class, as well as how to overcome some of the potential difficulties that teachers might encounter. Different approaches to films can be adopted, such as showing the whole film 
or focusing on short sequences, either with or without captions. The whole-film approach has the advantage of increasing students' confidence if they are able to comprehend the entire movie. The short-sequence approach, on the other hand, allows more time for language practice in class and students' attention is more likely to be held for the duration of one scene than it is for the duration of an entire film.

The decision of whether or not to use English-language captions also plays an important role during the viewing of a film. It has been suggested that captions improve overall comprehension while bridging the gap between reading and listening skills. However, captions might hinder the development of students' ability to make inferences and guess meaning based on a film's visual clues. Therefore, teachers have to decide how the students are going to view the film depending on the pedagogical objectives they are trying to meet.

When using a film in class, teachers can divide activities into three stages: pre-viewing, while-viewing, and post-viewing. Pre-viewing activities usually focus on preparing students for their experience with the film by activating their schemata. The main goal of while-viewing activities is to make sure students do not watch the movie passively. As for post-viewing activities, they can engage students in a wide variety of tasks, such as comprehension questions, discussion of the themes portrayed in the movie, specific language features, cultural differences, and so on.

Through the set of proposed guidelines, teachers will be able to visualize how theoretical principles can be applied in practice, and might even be encouraged to use films for the purpose of language teaching and learning. The criteria provided for the development of film-based material should also help teachers to feel more confident in selecting films and exploring their benefits to the fullest. Teachers will be able to set language- and communication-based goals, instead of showing films purely for the purpose of entertainment.

This investigation of the use of films in language teaching can serve as a starting point for further research. Since the proposed guidelines were developed for a specific course in Brazil, it would be interesting to design a material and evaluate how beneficial its application would be for students. The literature review could also be used to develop research on how teachers are currently using films in their classrooms. Finally, I believe this paper might enrich teachers' repertoire with insights and examples of how to use films, as well as encouraging reflection and discussion of their advantages and the different ways films could be applied to language learning. 


\section{REFERENCES}

ALTMAN, R. (1989). The Video Connection: Integrating Video into Language Teacbing. Boston: Houghton Mifflin Company.

ARCARIO, P. (1990). Selecting video materials. In: Stempleski, S. and Arcario, P. (eds.) Video in Second Language Teaching: Using, Selecting, and Producing Video for the Classroom. Teachers of English to Speakers of Other Languages, Inc. 109-122.

ATKINSON, D. (1999). TESOL and culture. TESOL Quarterly, v. 33, n 4, pp. 625-654.

BOXER, D. and PICKERING, L. (1995). Problems in the presentation of speech acts in ELT materials: the case of complaints. ELT Journal, v. 49, $\mathrm{n}^{\circ} 1$, pp. 44-58.

BROWN, H. D. (2007). Principles of Language Learning and Teaching. NY: Pearson.

BURNS, A. and HILL, D. (2013). Teaching Speaking in a Second Language. In: Tomlinson, B. (ed.) Applied Linguistics and Materials Development. London: Bloomsbury Publishing.

BYGATE, M. (1987). Speaking. Oxford: Oxford University Press.

CANNING-WILSON, C. (2000). Practical aspects of using video in the foreign language classroom. The Internet TESL Journal. http://iteslj.org/Articles/Canning-Video.html (accessed on 20/07/2015)

DE BOT, K., LOWIE, W. and VERSPOOR, M. (2005). Second Language Acquisition. An Advanced Resource Book. London: Routledge.

DONAGHY, K., and WHITCHER, A. (2015). How to Write Film and Video Activities (Kindle version). ELT Teacher 2 Writer. Retrieved from http://www.amazon.co.uk

DÖRNYEI, Z. and CSIZÉR, K. (1998). Ten commandments for motivating language learners: Results of an empirical research. Language Teaching Research, n 2, pp. $203-$ 229.

DÖRNYEI, Z. and USHIODA, E. (2001). Teaching and Researching Motivation. Pearson Education Ltd.

EKEN, A. (2003). 'You've got mail': a film workshop. ELT Journal, v. 57, nº 1, pp. 51-59.

ELLIS, R. (2005). Principles of instructed language learning. System, v. 33, pp. 209-224.

GARZA, T. (1991). Evaluating the use of captioned video material in advanced foreign language learning. Foreign Language Annals, v. 24, nº 3, pp. 239-258.

GASS, S. and MACKEY, A. (2015). Input, interaction, and output in second language acquisition. In: VanPatten, B. and Williams, J. (eds.) Theories in Second Language Acquisition. Routledge, pp. 180-200.

GASS, S. and SELINKER, L. (2001). Second Language Acquisition: An Introductory Course. Lawrence Erlbaum Associates.

GILMORE, A. (2007). Authentic materials and authenticity in foreign language teaching. Language Teaching, v. 40, pp. 97-118.

GOLDSTEIN, B. and DRIVER, P. (2015). Language Learning with Digital Video. Cambridge: Cambridge University Press.

HARMER, J. (2001). The Practice of English Language Teaching. Longman. 
HEDGE, T. (2000). Teaching and Learning in the Language Classroom. Oxford: Oxford University Press.

HERRON, C., MORRIS, M., SECULES, T., and CURTIS, L. (1995). A comparison study of the effects of video-based versus text-based instruction in the foreign language classroom. French Review, v. 68, pp. 775-795.

HINKEL, E. (1999). Culture in Second Language Teaching and Learning. Cambridge: Cambridge University Press.

HUA, Z. (2014). Exploring Intercultural Communication. Routledge.

HUGHES, R. (2010). Materials to develop the speaking skill. In: Harwood, N. (ed.) English Language Teaching Materials. Cambridge University Press, pp. 207-224.

ISTANTO, J. (2009). The use of films as an innovative way to enhance language learning and cultural understanding. Electronic Journal of Foreign Language Teaching, v. 6, n 1, pp. 278-290.

KING, J. (2002). Using DVD feature films in the EFL classroom. ELT Newsletter. http://www. eltnewsletter.com/back/February2002/art882002.htm (accessed on 03/06/2015)

KRAMSCH, C. (1993). Context and Culture in Language Teaching. Oxford: Oxford University Press.

KUSUMARASDYATI (2004). Listening, viewing and imagination: Movies in EFL classes. $2^{\text {nd }}$ International Conference on Imagination and Education. Vancouver.

MACDONALD, G. and MACDONALD, A. (1991). Variations on a theme: Film and ESL. Paper presented at the Annual Meeting of the Teachers of English to Speakers of Other Languages. New York.

MCGRATH, I. (2013). Teaching Materials and the Roles of EFL/ESL Teachers. Bloomsbury.

MISHAN, F. (2005). Designing Authenticity into Language Learning Materials. Bristol: Intellect Books.

NUNAN, D. (1999). Second Language Teaching \& Learning. Heinle \& Heinle.

PEGRUM, M., HARTLEY, L., and WECHTLER, V. (2005). Contemporary cinema in language learning: from linguistic input to intercultural insight. The Language Learning Journal, v. 32, $\mathrm{n}^{\circ} 1$, pp. 55-62.

PORTER, D. and ROBERTS, J. (1981). Authentic listening activities. ELT Journal, v. 36, nº 1, pp. 37-47.

SHERMAN, J. (2003). Using Authentic Video in the Language Classroom. Cambridge: Cambridge University Press.

STEMPLESKI, S. (1990). Teaching communication skills with authentic video. In: Stempleski, S. and Arcario, P. (eds.) Video in Second Language Teacbing: Using, Selecting, and Producing Video for the Classroom. Teachers of English to Speakers of Other Languages, Inc, pp. 7-24.

STEMPLESKI, S. and ARCARIO, P. (1990). Video in Second Language Teaching: Using, Selecting, and Producing Video for the Classroom. Teachers of English to Speakers of Other Languages, Inc. 
STOLLER, F. (1990). Using video in theme-based curricula. In: Stempleski, S. and Arcario, P. (eds.) Video in Second Language Teaching: Using, Selecting, and Producing Video for the Classroom. Teachers of English to Speakers of Other Languages, Inc, pp. 25-46.

SWAIN, M. (2000). The output hypothesis and beyond: Mediating acquisition through collaborative dialogue. In: Lantolf, J.P. (ed.) Sociolcultural Theory and Second Language Acquisition. Oxford: Oxford University Press, pp. 97-114.

TOMLINSON, B. (2003). Developing principled frameworks for materials development. In: Tomlinson, B. (ed.) Developing Materials for Language Teaching. Continuum, pp. 107 129.

TOMLINSON, B. (2010). Principles of effective materials development. In: Harwood, N. (ed.) English Language Teaching Materials: Theory and Practice. Cambridge: Cambridge University Press.

UR, P. (1996). A Course in Language Teaching. Cambridge: Cambridge University Press.

VAEZI, R., TABATABAEI, S. and BAKHTIARVAND, M. (2014). A comparative study of speech acts in the textbooks by native and non-native speakers: a pragmatic analysis of New Interchange Series vs. locally-made EFL textbooks. Theory and Practice in Language Studies, v. 4, n 1, pp. 167-180.

WIDDOWSON, H. G. (1978). Teaching Language as Communication. Oxford: Oxford University Press.

WILKINS, D. A. (1974). Second Language Learning and Teacbing. London: Edward Arnold.

WILLIAMS, E. (1984). Reading in the Classroom. London: Macmillan Publishers Ltd.

WILLIAMS, M. and BURDEN, R. L. (1997). Psychology for Language Teachers. Cambridge: Cambridge University Press.

Recebido: 21/10/2015

Aceito: 07/03/2016 